\title{
Necrotic Tongue: A Rare Manifestation of Giant Cell Arteritis
}

SCOTT JENNINGS, MBBS(Hons), Surgical Registrar, Moruya District Hospital, Moruya; SANJAY SINGH, FRACS FRCS(UK), Consultant, General Surgeon, Mogo Day Surgery, Mogo, New South Wales, Australia. Address correspondence to Dr. Jennings, Moruya District Hospital, Moruya, New South Wales 2537, Australia; E-mail: scott.b.jennings@gmail.com. J Rheumatol 2011;38:2688; doi:10.3899/jrheum.110780

Necrotic tongue is described as a rare manifestation of giant cell arteritis $(\mathrm{GCA})^{1,2,3}$ requiring immediate empirical steroid treatment.

A 79-year-old woman was referred by her general practitioner for urgent surgical review of a necrotic tongue. She had been feeling fatigued for the previous 3 weeks and complained of throat and bilateral occipital neck pain that progressed to include dental pain, jaw claudication, and difficulty opening her mouth. She denied visual symptomatology, but this was complicated by a background of cataracts and macular degeneration. However, she believed her vision deteriorated during this illness. She had no allergies and no oral trauma; the tongue had become necrotic 4 days prior to review.

On examination, she was dysphagic; the tongue was clearly demarcated between healthy and necrotic tissue, painful with speech and touch, insensate to taste, and productive of a putrid odor. A literature search revealed this to be an extremely rare manifestation of $\mathrm{GCA}^{1,2}$. She was placed on 6-hourly intravenous ticarcillin/clavulanate and received 8-hourly mouthwashes. Blood investigations revealed an erythrocyte sedimentation rate of $75 \mathrm{~mm} / \mathrm{h}$. Discussion with the rheumatology specialist led to immediate empirical steroid treatment. Steroid treatment resulted in almost immediate arrest of the necrosis; a subsequent temporal artery biopsy confirmed GCA.

After a week of treatment, there was significant improve-

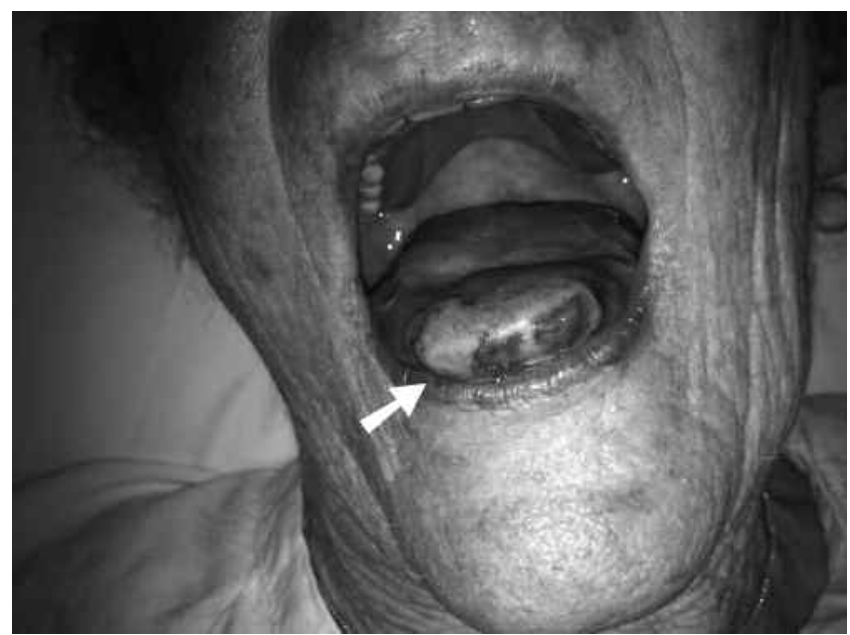

Figure 1. Anterior tongue necrosis on initial review.

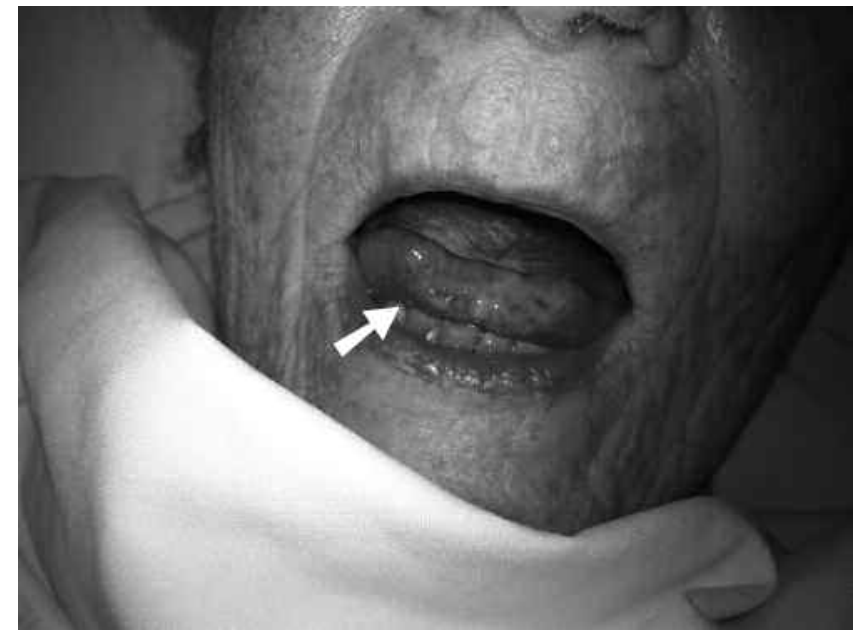

Figure 2. Recession of pain and symptoms and auto-amputation of the necrotic tongue segment after 1 week of steroid treatment.

ment in sensation and speech, with the necrotic segment of tongue completely auto-amputating (Figure 2). The patient has since been followed by the rheumatology service and continues improving. A paucity of similar cases in the literature followed a comparable course ${ }^{1,2,3}$. It is recommended that clinicians be alert to this rare manifestation of GCA, enabling prompt steroid therapy and involvement of a rheumatology specialist.

\section{REFERENCES}

1. Brodmann M, Dorr A, Hafner F, Gary T, Pilger E. Tongue necrosis as first symptom of giant cell arteritis (GCA). Clin Rheumatol 2009;28 Suppl 1:S47-9.

2. Kusanale A, Boardman H, Khoshnaw H. Tongue necrosis: A rare presentation of temporal arteritis. Age Ageing 2008;37:119.

3. Schurr C, Berthele A, Burghartz M, Kiefer J. Spontaneous bilateral necrosis of the tongue: A manifestation of giant cell arteritis? Eur Arch Otorhinolaryngol 2008;265:993-8. 